Research Article

\title{
Research on Innovation Efficiency of Listed Companies in Development Zone Based on the Three-Stage DEA-Tobit Model: A Case Study of Hubei Province
}

\author{
Peng Xu $\mathbb{D}$, Fan Luo, Ziyue Zhang, and Hongyi Xu $\mathbb{D}$ \\ School of Management, Wuhan University of Technology, Wuhan, Hubei, China \\ Correspondence should be addressed to Peng Xu; lambency.xu@gmail.com and Hongyi Xu; steven_64@163.com
}

Received 17 February 2020; Revised 24 April 2020; Accepted 25 May 2020; Published 18 July 2020

Academic Editor: Filippo Cacace

Copyright ( 2020 Peng Xu et al. This is an open access article distributed under the Creative Commons Attribution License, which permits unrestricted use, distribution, and reproduction in any medium, provided the original work is properly cited.

\begin{abstract}
This study applies 3-stage data envelopment (DEA) of 24 listed companies in the development zone of Hubei Province from 2012 to 2017 based on the panel data; we used the DEA-Tobit model and regression analysis method on the sample in order to measure the factors affecting the innovation efficiency of listed companies and the efficiency of corporate innovation. The results demonstrated that the innovation efficiency of listed companies in the development zone of Hubei Province is relatively low. It is necessary to improve the innovation system of the development zone and give the full initiative to the role of corporate innovation as a mainstay. The four environmental variables of the number of enterprises, government subsidies, foreign direct investment in the development zone, and fixed asset investment have a significant impact on innovation efficiency. The enterprise size, operating capacity, and state-owned shares of the company have a significant positive impact on the innovation efficiency. But the number of years of the establishment has a significant negative impact on innovation efficiency. Moreover, the quality of the workers is not significant. Therefore, we must increase government investment in innovation to expand the scale of listed companies in the development zone, improve the environment for foreign investment, further strengthen the construction of talented people of companies, and enhance the original ability of innovation.
\end{abstract}

\section{Introduction}

There are 136 development zones of various types in Hubei Province, 21 of them are at the national developed level, and the total economic volume of the development zones reached more than half of the total economic aggregate of the province. The industrial output value accounts for more than $50 \%$ of the country's, and it is an important support point and locomotive for the province's economy. The listed companies in the development zone are the strongest, largest, and most innovative groups among the enterprises in the development zone. Their ability to innovate and develop is indispensable for the sustainable and rapid development of the development zone. Continuous innovation will improve technical efficiency and promote better and faster development of development zone; innovation is also conducive to promoting the resumption of production after the epidemic in Hubei Province and also is helpful for the Hubei government to achieving the short-term and longterm economic goals. Since Schumpeter first proposed the theory of innovation in 1912 [1], this field of research on innovation development has made great progress. The research on the innovation efficiency of listed companies mainly focuses on the innovation capabilities $[2,3]$, innovation efficiency [4], influencing factors [5], and efficiency measures [6, 7]. In terms of influencing factors, many scholars' research studies show that technological innovation [8], research and development investment [9], scale efficiency [10], etc. will affect the company's innovation efficiency. In terms of evaluation methods, there are mainly two types of parametric and nonparametric methods [11]. Parametric methods are represented by stochastic frontier production function analysis (SFA) [12], and nonparametric laws are based on data envelopment analysis (DEA) [13]. In 
order to reflect the true level of corporate innovation efficiency, Farrel proposed a new method based on data envelopment analysis (DEA) to incorporate environmental factors and random errors into the efficiency measure, which is a three-stage DEA model [14]. This method has been widely used [15].

So far, traditionally, some of the literature studied the innovation efficiency of China's listed companies [11]. Although their research studies have achieved obvious results, when it comes to select models and variables, there are still strong subjective factors affecting the selection, which cannot truly reflect the innovation efficiency of listed companies in the development zone, and researchers cannot conduct multioutput analysis and do not comprehensively evaluate the listed companies in the development zone. Evaluation of innovation efficiency did not exclude the interference of environmental factors of the innovation efficiency of listed companies, and the efficiency value obtained may be affected by accidental factors that are not conducive to the improvement measures brought for the award and the same as other problems.

The research field of DEA has grown rapidly since the pioneering paper of Farrell [14] and Charnes et al. [15]. However, a pure analysis method based on the traditional DEA model cannot eliminate the effects of environmental factors and random error. Fried et al. come up with a new method, a three-stage DEA model based on data envelopment analysis (DEA) that incorporates environmental factors and random errors into efficiency measures [16]. Now, the three-stage DEA model is regarded as a good method for researchers to study the performance of different industries and listed companies. Ebrahimnejad et al. [17] proposed a three-stage DEA model with two independent parallel stages linking to a third final stage to calculate the efficiency of the banking industry. Lin [18] analyzed the output and input efficiency of the information industry in China based on the three-stage DEA model in 2009. Lin and Li's research believed that the listed sample technical efficiency of companies of debt financing has somewhat improved compared with the figure obtained before the input variables are adjusted and that the uneven level of listed real estate pure technical efficiency of companies of debt financing in China shows the obvious difference. Liu and $\mathrm{Li}$ measured the performance of the Internet Company of China using a three-stage DEA model, and the result shows that the Chinese Internet company is affected by external environmental factors [19]. $\mathrm{Qu}$ examines the technology innovation efficiency of Chinese listed companies based on the three-stage DEA model to the data from 2008 to 2015 of Chinese companies listed on the market. The research shows that the technology innovation efficiency of the listed companies in China is generally low [11]. Liu et al. selected 31 listed companies in China's cultural media as samples and used the three-stage DEA model and found that their overall efficiency, as well as pure technical efficiency and standardization efficiency, has been improved [20, 21].

But it should be pointed out that the three-stage DEA is not limited to the single output mode; it can not only overcome the need for artificial comprehensive weighting (FCE) and stochastic frontier analysis (SFA) but can also overcome the analytic hierarchy process (AHP); decisionmaking quality will be reduced or even failed due to unreasonable selected elements or incorrect relations between elements; at the same time, it can overcome the problem of single-stage DEA and two-stage DEA so that these two cannot homogenize the nonoperating factors (external environment and random errors) of the decision-making unit which is insufficient, excluding the influence of external factors so that each decision-making unit will be under the same environment and random factors [22].

In summary, the three-stage DEA method in this paper is able to overcome the above problems. In addition, from all the literature we researched, no literature has been found using the three-stage DEA method to study the innovation efficiency of listed companies in the development zone. We believe that the innovation of this paper is obvious. Therefore, this paper takes the development zone of Hubei Province as an example to study the innovation efficiency of listed companies in the development zone and systematically analyzes the problems and influencing factors of the development of innovation efficiency in the development zone; we formulate development policies and measures which are appropriate for improving the innovation system construction of the development zone. We primarily focus on the following issues. We aim to provide further insights into which and how the factors affect the innovation efficiency of listed companies in the development zone of Hubei Province and in what way the government can formulate appropriate development policies to improve the innovation system construction of the development zone, etc. Therefore, this research has important practical significance and reference value.

The rest of the paper is organized as follows. Section 2 presents the research design including defining the input, output, environment variables and selecting samples and data sources. Section 3 characterizes the measurement and analysis of innovation efficiency based on the three-stage DEA model. Section 4 presents the studies and analysis of factors affecting innovation efficiency based on the Tobit model. Section 5 outlines the conclusions, related policy recommendations, and research limitations.

\section{Research Design}

2.1. Research Methods. Because the traditional DEA model cannot exclude the influence of environmental variables and random factors on the efficiency of decision-making units, this paper uses the three-stage DEA model proposed by Fried et al. [16]. We construct a three-stage DEA model at first, then determine the input, output, and environmental variable index, process the corresponding data, and measure the innovation efficiency of listed companies in the Hubei Development Zone. At last, we use innovation efficiency as the explanatory variable. The Tobit model was used to study the innovation efficiency of the enterprise influencing factors. 
2.1.1. The First Stage: DEA-BCC Model. In the first stage, the traditional DEA method is used for calculation, and the original input-output data are used for initial efficiency evaluation. This paper adopts the BCC model "with variable returns to scale" proposed by Banker et al. [23] and Charnest et al. to measure the initial input-output data for DMU technical efficiency [15]. The BCC model was adopted in most literature in most of the three-stage DEA models [24].

2.1.2. The Second Stage: SFA Model. Through this stage, an SFA (Stochastic Frontier Analysis) model was structured to study the influence of environment variables. The total relaxation amount (the sum of radial and nonradial relaxation amounts) corresponding to each input is used as the dependent variable, and all environmental variables are used as independent variables. The relaxation amount of each input is individually subjected to SFA, and a total of $i$ are established. The $i^{\text {th }}$ regression equation is

$$
s_{i j}=f^{i}\left(z_{j} ; \beta^{i}\right)+v_{i j}+u_{i j}, \quad j=1, \ldots, n, i=1, \ldots, m,
$$

where $s_{i j}$ is the slack of the $i^{\text {th }}$ input of the $j^{\text {th }}$ decision unit; $P$ is the number of environment variables; $z_{j}=\left[z_{1 j}, z_{2 j}, \ldots, z_{P j}\right], j=1,2, \ldots, n ; \beta^{i}$ is a parameter to be estimated; $v_{i j}+u_{i j}$ is a mixed error, where $v_{i j} \sim N\left(0, \sigma_{v_{i}}^{2}\right)$ reflects random errors and $u_{i j} \geq 0$ reflects management inefficiency; we assume that $u_{i j}$ follows a seminormal distribution $u_{i j} \sim N^{+}\left(0, \sigma_{u_{i}}^{2}\right)$.

In order to eliminate the influence of random error, it is necessary to separate the random error from the management inefficiency. In this paper, we use the formula derived by Luo to calculate the conditional estimate of management inefficiency $\widehat{E}\left[u_{\text {descriptions }} \mid v_{i j}+u_{i j}\right][20]$; then, the model is structured as follows:

$$
E\left(u_{j} \mid \varepsilon_{j}\right)=\frac{\lambda \sigma}{1+\lambda^{2}}\left[\frac{\phi\left(\varepsilon_{j} \lambda / \sigma\right)}{\Phi\left(\varepsilon_{j} \lambda / \sigma\right)}+\frac{\varepsilon_{j} \lambda}{\sigma}\right], \quad j=1, \ldots, n,
$$

where $\varepsilon_{j}=v_{j}+u_{j}, \sigma_{*}^{2}=\sigma_{u}^{2} \sigma_{v}^{2} / \sigma^{2}, \lambda=\sigma_{u} / \sigma_{v}$ and $\phi(\cdot)$ and $\Phi(\cdot)$ are the density function and distribution of the standard normal distribution. The conditional estimate to obtain random errors can be written as

$$
\begin{array}{r}
\widehat{E}\left[v_{i j} \mid v_{i j}+u_{i j}\right]=s_{i j}-z_{j} \widehat{\beta^{i}}-\widehat{E}\left[u_{i j} \mid v_{i j}+u_{i j}\right], \\
j=1, \ldots, n, i=1, \ldots, m .
\end{array}
$$

2.1.3. The Third Stage: Adjust the Input Value and the Original Outputs into the DEA Model and Run It Again. In the third stage, the adjusted input value and the original output value are brought into the DEA-BCC model again. We can say that combining different inputs and outputs will produce a different efficiency ranking of companies. The adjusted innovation efficiency is the effect of stripping the external environment and random errors. At this time, the efficiency is only affected by the enterprise's self-management level.

2.2. Variable Definition. According to the research of Wang et al. and Qu et al., this paper divides innovation input into research and development input and production input. Similarly, we also divide the innovation output into technical output and marketing output $[11,25]$. Based on the characteristics of the development zone and the actual situation of the listed company, we finally determine three input indicators, two output indicators, and four environmental variable indicators, as shown in Table 1.

2.2.1. Innovation Input Indicators. The input factors mainly included human input and capital input. In this study, these factors will directly affect the innovation efficiency of the enterprise. This paper has selected a total of three input indicators. The indicators described as follows reflect the selected reasons:

(1) Technical Staff (Person). Most literature generally chooses R\&D personnel as an indicator of the technical personnel of listed companies; technical personnel is one of the essential elements of enterprise investment and also one of the indispensable elements of enterprise innovation investment $[11,19]$. In this paper, we selected the number of technical personnel in the annual report of listed companies as the human input element in $R \& D$ investment

(2) R\&D Investment (Million Yuan). One of the important input elements in independent innovation of enterprises is $\mathrm{R} \& \mathrm{D}$ funds $[11,19]$. This paper selects the R\&D expenditure input index of listed companies at the end of each year as the capital input element of $\mathrm{R} \& \mathrm{D}$ investment. Because innovation output is different from general production, the current innovation output is not only affected by the current input but also affected by the previous innovation input; that is, the current input not only affects the current but also affects the future of innovation output. Since the R\&D expenditure data disclosed in the annual report is flow data, it needs to be converted into a stock index. In the estimation of stock, the internationally common method is the perpetual inventory method. This paper makes some adjustments based on the basic formula. The calculation formula is

$$
K_{j t}=(1-\delta) K_{j, t-1}+E_{j t}
$$

where $K_{j t}$ represents the R\&D capital stock of the $j^{\text {th }}$ company in the $t^{\text {th }}$ year, $K_{j, t-1}$ represents the R\&D capital stock of the $j^{\text {th }}$ company in the $t-1$ year, $E_{j t}$ represents the R\&D funding input of the $j^{\text {th }}$ company in the $t$ year, and $\delta$ represents depreciation rate. According to the adjusted method proposed by $\mathrm{Wu}$ method, he set $\delta$ to $15 \%$ [26]. 
TABLE 1: Related indicators of innovation efficiency measurement.

\begin{tabular}{|c|c|c|}
\hline Reference layer & & Indicator layer \\
\hline Innovation input variables & $\mathrm{R} \& \mathrm{D}$ & $\begin{array}{c}\text { Technician } \\
\text { R\&D investment }\end{array}$ \\
\hline & Production input & All employees of the enterprise \\
\hline Innovation output variable & $\begin{array}{c}\text { Technical output } \\
\text { Marketing output }\end{array}$ & $\begin{array}{c}\text { Number of invention patents granted } \\
\text { Total operating income }\end{array}$ \\
\hline Environment variables & $\begin{array}{l}\text { Number of companies } \\
\text { Investment in fixed assets } \\
\text { Foreign direct investment } \\
\text { Government subsidy }\end{array}$ & $\begin{array}{l}\text { Number of listed companies in the industry } \\
\text { Development zone investment in fixed assets } \\
\text { Foreign Direct investment in development zones } \\
\text { Government subsidies for listed companies }\end{array}$ \\
\hline
\end{tabular}

According to the practice of Hall and Jones, the calculation formula for the base year R\&D capital stock was structured as follows:

$$
K_{j, 2012}=\frac{E_{j, 2012}}{\left(\delta+g_{j}\right)},
$$

where $K_{j, 2012}$ is the base R\&D capital stock of the $j^{\text {th }}$ company in 2012, $E_{j, 2012}$ represents the R\&D funding investment of the $j^{\text {th }}$ company in 2012, and $g_{j}$ represents the year of the $j^{\text {th }}$ company's R\&D investment average growth rate.

This paper uses 2012 as the base period and then calculates the annual average growth rate of each company's R\&D expenditure in 2013-2017. We use formula (5) to obtain the company's 2012 base period R\&D capital stock and then bring it into formula (4). At last, we can obtain the R\&D capital stock of each company from 2013 to 2017.

(3) All Employees (Persons) of the Enterprise. After new technology had been developed, the participation of all employees in the enterprise is an important factor for the successful transformation, application, and promotion of technology [11]. Different from the input of technical personnel, the content of employee's work is not to develop new technologies but to apply and popularize new technologies to benefit the enterprise in the further. Therefore, this paper selects the total number of employees in the company's annual report as a factor of productive input

2.2.2. Innovation Output Indicators. Innovation output is mainly considered from technical output and marketing output. The descriptions for inputs and outputs are as follows:

(1) The Number of Invention Patents Granted (Number). Three types of patents in China can be considered: invention patents, utility model patents, and design patents. Among them, the most representative of an enterprise's innovation ability and innovation strength are invention patents $[11,19]$. Therefore, the number of invention patents authorized is selected as the technical output index
(2) Total Operating Income (Million Yuan). For listed companies, the development of an enterprise is inseparable from innovation, the ultimate purpose of innovation is to bring economic benefits to the enterprise, and innovation will have an impact on the company's subsequent R\&D investment activities. The reflection of the company's business results at a certain stage is financial indicators, which determines the company's future cash flow and will also affect the company's R\&D investment [11]. Therefore, we select the total operating income of a listed company at the end of the year as an indicator of marketing output

2.2.3. Environment Variables. In the second stage, the environmental variables eliminated are not subject to corporate subjectivity and management; the environmental variables are the factors that objectively affect the efficiency of corporate innovation, including macro national policies, regional economies, and micro corporate characteristics. When we select the environmental variables, we use a macro perspective; combined with the specific environment of listed companies in the development zone, the following indicators were selected as environmental variables:

(1) The Number of Enterprises. The increase in the number of enterprises is beneficial to $\mathrm{R} \& \mathrm{D}$ expenses and $R \& D$ personnel. In order to develop better in the future, enterprises need to increase their investment, but it may also cause waste in the process of input resources. Increasing investment will affect the innovation efficiency of enterprises [11]. According to the 2012 CSRC industry classification standard, we select the number of listed companies in the corresponding industry

(2) Investment in Fixed Assets (100 Million Yuan). Investment in fixed assets in the development zone can provide enterprises with advanced production equipment and services. The investment creates an excellent environment for innovation and affects the innovation efficiency of enterprises to a certain extent [19]. In this study, we choose the total investment in fixed assets of the development zone where the enterprise is located 
(3) Foreign Direct Investment (Million USD). In theory, foreign investment will promote the level of innovation efficiency of enterprises through technology spillovers. Foreign investment will bring technology spillover effect; therefore, it will indirectly improve the level of technical efficiency of enterprises [11]. In our study, due to the lack of data on foreign direct investment in some development zones, this paper selects the sum of foreign direct investment in all development zones in the city where the listed company is located instead

(4) Government Subsidies (Ten Thousand Yuan). Government subsidy refers to a policy in which the government provides financial subsidies to innovative companies to encourage innovation $[11,21]$. In development zones, government subsidies are also used to attract high-tech enterprises to join and provide guarantees for enterprise development. Therefore, government subsidies are always included in the current profit and the loss of the listed company's annual report

In order to eliminate the possible impact of different data dimensions, we standardize the four environmental variables. The formula can be expressed as follows:

$$
Y_{j}=\frac{\left(X_{j}-\min X_{j}\right)}{\left(\max X_{j}-\min X_{j}\right)}, \quad j=1,2,3,4,
$$

where $X_{j}$ is the initial value of the $j^{\text {th }}$ environment variable and $Y_{j}$ is the result of the $j^{\text {th }}$ environment variable processing.

2.3. Sample Selection and Data Sources. The data of the annual report of listed companies we need in this study are from the Guotai'an database and the "Hubei Statistical Yearbook." The sample selection of listed companies is mainly based on the following: (1) Registration places in Hubei Province Economic and Technological Development Zone or High-tech Industrial Development Zone are included. (2) We exclude ST and *ST companies because these listed companies have abnormal financial conditions and will affect the research conclusions. (3) The R\&D expenditures of listed companies in Hubei Development Zones were seriously deficient before 2012. Therefore, we choose the data range from 2012 to 2017. (4) Enterprises missing main indicators will be eliminated. Finally, we screen panel data of 24 listed companies from 2012 to 2017.

Because the innovation input of enterprises is lagging, according to the research of $\mathrm{Yu}$ et al., the innovation output index is two periods behind the innovation input index $[26,27]$. The data of input indicators in this paper are from 2012 to 2015, and the data of output indicators are from 2014 to 2017. The descriptive statistics of the development zones and industry classification codes of 24 listed companies are presented in Table 2.

\section{Measurement and Analysis of Innovation Efficiency Based on the Three-Stage DEA Model}

3.1. Results of Traditional DEA in the First Stage. At this stage, using the innovation efficiency of the listed companies in the Hubei Development Zone, three inputs and two outputs are calculated by the traditional DEA-BCC model and the classic DEAP 2.1 software; after being calculated, we can see the average annual efficiency obtained in Table 3.

First of all, the result shown in Table 3 indicates that the comprehensive technical efficiency of the 24 listed companies in the Hubei Development Zone from 2012 to 2015 was low, the average value of each column only reaches 0.516 , and the efficiency of listed companies is all below 0.7. There was a certain distance from the frontier of efficiency distance and there is a lot of room for improvement. The average value of pure technical efficiency is 0.722 , and the average value of scale efficiency is 0.713 , which indicates that the overall technical inefficiency is caused by improper technology management, insufficient resource allocation, and failure to achieve scale effects. Second, as for the change in tendency, comprehensive technical efficiency in 2012-2015 was decreased. The reason for the reduced efficiency of comprehensive technical from 2012 to 2013 and from 2014 to 2015 is to reduce the pure technical efficiency, indicating that corporate management and resource configuration need to be improved. The reason for the 2013-2014's comprehensive technical efficiency decreases is the size reduction, indicating that the effect of the year did not meet the enterprise scale.

From the perspective of a single listed company, Guangxun Technology, Renfu Medicine, Donghu Hightech, Yangtze Telecom, FiberHome, Sanan Optoelectronics, and Dongfeng Motor have a total technical efficiency of $0.8-1$, about $1 / 3$ of the total. There are 7 companies in the range of $0.5-0.8$ and 10 companies in the range below 0.5 . There are 2 companies with a comprehensive technical efficiency of 1,6 with a pure technical efficiency of 1 , and 2 with a scaling efficiency of 1. From 2012 to 2015, only Guangxun Technology and FiberHome have reached the forefront of comprehensive technical efficiency.

3.2. Phase 2 SFA Results. In the second stage, SFA models are used to analyze each year separately. We take the number of enterprises, government subsidies, foreign direct investment, and fixed asset investment as independent variables, and we establish a random frontier analysis model for each year of the three input relaxation values obtained in the first stage. When the coefficient is positive, it means that increasing the environment variable will promote the increase of input slack value, leading to an increase in waste, which is not conducive to the improvement of efficiency. Conversely, when the coefficient is negative, it means that increasing the environment variable will reduce the input slack value and 
TABLE 2: Development zone and industry classification codes of 24 listed companies.

\begin{tabular}{lccc}
\hline Stock code & Company abbreviation & Development zone & 2012 SFC industry code \\
\hline 000852 & Petrochemical machinery & Wuhan-Donghu high-tech zone & C35 \\
000988 & Huagong technology & Wuhan-Donghu high-tech zone & C39 \\
002281 & Light Motion technology & Wuhan-Donghu high-tech zone & C39 \\
002377 & Guochuang high-tech & Wuhan-Donghu high-tech zone & C25 \\
002414 & Gaode infrared & Wuhan-Donghu high-tech zone & C38 \\
300018 & Zhongyuan shares & Wuhan-Donghu high-tech zone & C34 \\
300161 & Central China CNC & Wuhan-Donghu high-tech zone & F51 \\
300184 & Liyuan information & Wuhan-Donghu high-tech zone & C39 \\
300205 & Celestial information & Wuhan-Donghu high-tech zone & C39 \\
300323 & Huacan optoelectronics & Wuhan-Donghu high-tech zone & C27 \\
600079 & Renfu medicine & Wuhan-Donghu high-tech zone & E48 \\
600133 & Donghu high-tech & Wuhan-Donghu high-tech zone & C39 \\
600345 & Changiang communications & Wuhan-Donghu high-tech zone & C39 \\
600355 & Jinglun electronics & Wuhan-Donghu high-tech zone & C29 \\
600498 & Beacon communication & Wuhan-Donghu high-tech zone & C26 \\
002694 & Gu Di technology & Ezhou-economic development zone & C35 \\
300054 & Dinglong shares & Wuhan-economic development zone & C30 \\
300276 & Mitutoyo intelligent & Huangshi-economic development zone & \\
600293 & Three Gorges new materials & Yichang-Dangyang economic development zone & \\
600703 & Sanan optoelectronics & Jingzhou-economic development zone & \\
002013 & AVIC & Xiangyang-high-tech zone & \\
000821 & Jingshan Light Machine & Jingmen-Jingshan economic development zone & \\
600006 & Dongfeng Motor & Wuhan-economic development zone & \\
000760 & Steyr & Jingzhou-public security economic development zone & C35 \\
\hline
\end{tabular}

TABle 3: Mean annual innovation efficiency of 24 listed companies in the Hubei Development Zone.

\begin{tabular}{lccc}
\hline Year & Comprehensive technical efficiency & Pure technical efficiency & Scale efficiency \\
\hline 2012 & 0.612 & 0.745 & 0.795 \\
2013 & 0.563 & 0.710 & 0.798 \\
2014 & 0.449 & 0.727 & 0.609 \\
2015 & 0.439 & 0.707 & 0.651 \\
Mean & 0.516 & 0.722 & 0.713 \\
\hline
\end{tabular}

reduce the waste of input, which is conducive to the improvement of efficiency. The SFA regression result and analysis are obtained by using frontier 4.1 (see Table 4 ).

It can be seen from Table 4 that the coefficients of the three input relaxation values for each of the environmental variables in the past 4 years have passed the $5 \%$ significance test, which indicates that the environmental variables we selected in this paper are reasonable. The environmental variables and random errors are important for corporate innovation, and the impact of efficiency is significant. The equations of the four environmental variables for the technician's relaxation value did not pass the test in 2015 . Therefore, in the third stage, we will not make any adjustments to the technician input value in 2015 .

Vertically, first of all, we can be sure that the number of companies always has a significant positive impact on the slack value of R\&D capital stock; this indicates that an increase in the number of companies in the industry will lead to a waste of R\&D capital and is not conducive to the innovation efficiency of companies. The increase in the intensity of competition between companies has caused companies to blindly increase investment in innovation; this action cannot be translated into corresponding output.
Second, in the four years of the fixed asset investment in the development zone, three years of them have a significant positive impact on the three types of input relaxation values; this indicates that the investment of the development zone in its own facilities and services will cause waste of R\&D funds and personnel; it is not conducive to improving efficiency. Third, foreign direct investment in the development zone has had two impacts on the three types of input slack. This means the technological spillover effect of foreign direct investment on the enterprise has enabled the enterprise to allocate resources more reasonably, but the blind introduction of foreign investment will also cause the waste of invested resources to the enterprise. Fourth, in four years of government subsidies, three years of them shows a significant positive impact on the three types of input slack. The reason for it might be that the dependence of enterprises on the government has caused waste and unreasonable use of investment resources.

3.3. DEA Results after Adjusting Investment in the Third Stage. Due to the results of the second stage SFA, we adjust the input value of all enterprises to the same level and external 
TABLE 4: Results of relevant parameters using the SFA model from 2012 to 2017.

\begin{tabular}{|c|c|c|c|c|c|c|}
\hline \multicolumn{7}{|c|}{ The year 2012} \\
\hline & \multicolumn{2}{|c|}{ R\&D capital stock slack } & \multicolumn{2}{|c|}{$\begin{array}{l}\text { Relaxation value of all } \\
\text { employees in the enterprise }\end{array}$} & \multicolumn{2}{|c|}{ Technician relaxation value } \\
\hline & Coefficient & $T$ value & Coefficient & $T$ value & Coefficient & $T$ value \\
\hline Constant term & -78.190 & -37 & -3676.014 & -46 & -389.212 & -164 \\
\hline Number of companies & 69.814 & 76 & 647.049 & 651 & 11.919 & 2.78 \\
\hline Investment in fixed assets & 309.354 & 327 & 17653.580 & 51 & 2267.552 & 785 \\
\hline Foreign direct investment & -213.276 & -282 & -9395.036 & -79 & -1218.832 & -1747 \\
\hline Government subsidy & 20.439 & 18 & 1832.107 & 4.6 & 181.544 & 63 \\
\hline Sigma-squared & 14973.585 & 14986 & 11538049 & 11542640 & 202812.3 & 202809 \\
\hline Gamma & 0.9999999 & 154338 & 0.9999999 & 851283 & 0.9999972 & 125817 \\
\hline Log-likelihood & \multicolumn{2}{|c|}{-131} & \multicolumn{2}{|c|}{-213} & \multicolumn{2}{|c|}{-162} \\
\hline \multicolumn{7}{|c|}{ The year 2013} \\
\hline Constant term & -80.559 & -90 & -1022.431 & -1080 & 66.687 & 94 \\
\hline Number of companies & 123.185 & 135 & 56.712 & 4721 & -134.399 & 352 \\
\hline Investment in fixed assets & 98.591 & 99 & 3844.913 & 22 & 319.119 & -51 \\
\hline Foreign direct investment & -127.364 & -132 & -2917.641 & 1204 & -330.789 & 148 \\
\hline Government subsidy & 111.382 & 111 & 5494.703 & -1427 & 877.628 & -377 \\
\hline Sigma-squared & 19357.798 & 19357 & 5917432.6 & 5917424 & 284045.4 & 245718 \\
\hline Gamma & 0.9999999 & 77 & 0.9999999 & 8964383 & 0.9999999 & 103130300 \\
\hline Log-likelihood & \multicolumn{2}{|c|}{-135} & \multicolumn{2}{|c|}{-206} & \multicolumn{2}{|c|}{-160} \\
\hline \multicolumn{7}{|c|}{ The year 2014} \\
\hline Constant term & -111.985 & 5.2 & -476.988 & -13 & -302.608 & -302 \\
\hline Number of companies & 110.905 & 14 & 873.191 & -51 & 325.760 & 325 \\
\hline Investment in fixed assets & -84.161 & -57 & -1274.168 & 12 & -67.630 & -67 \\
\hline Foreign direct investment & 35.054 & 18 & 301.777 & 71 & 23.149 & 23 \\
\hline Government subsidy & 301.096 & 118 & 1635.974 & 446 & 388.014 & 388 \\
\hline Sigma-squared & 27955.047 & 28018 & 2394380.6 & 2394373 & 119852.6 & 119852 \\
\hline Gamma & \multirow{2}{*}{\multicolumn{2}{|c|}{$\begin{array}{r}0.9999999 \\
-141\end{array}$}} & \multirow{2}{*}{\multicolumn{2}{|c|}{-193}} & 0.9880079 & 10 \\
\hline Log-likelihood & & & & & \multicolumn{2}{|c|}{-159} \\
\hline \multicolumn{7}{|c|}{ The year 2015} \\
\hline Constant term & -131.693 & -108 & -3613.280 & -67 & -147.622 & -147 \\
\hline Number of companies & 115.129 & 125 & -179.221 & -12 & -112.713 & -112 \\
\hline Investment in fixed assets & 5.454 & 13 & 6763.365 & 110 & 1755.248 & 1755 \\
\hline Foreign direct investment & 12.941 & 18 & -2783.636 & -22 & -1179.371 & -1179 \\
\hline Government subsidy & -102.427 & -105 & -103.446 & -2.6 & -181.919 & -181 \\
\hline Sigma-squared & 42157.164 & 42157 & 7419775.3 & 7419670 & 146753.5 & 146753 \\
\hline Gamma & 0.9999961 & 1109210 & 0.9999999 & 666463 & 0.09 & 0.09 \\
\hline Log-likelihood & \multicolumn{2}{|c|}{-144} & \multicolumn{2}{|c|}{-211} & \multicolumn{2}{|c|}{-176} \\
\hline
\end{tabular}

environment, and we use the DEA model again to calculate the innovation efficiency of 24 listed companies in Hubei Development Zone and then the efficiency values compared with the preadjustment. The average innovation efficiency before and after each year of adjustment is shown in Table 5.

From the results shown in the table, overall, from the data of 2012 to 2015, a four-year average of listed companies of the comprehensive technical efficiency after the adjustment has been improved, indicating that the preadjustment is mainly affected by adverse environmental factors; it will make the underestimation of the overall technical efficiency of the enterprise. The adjusted pure technical efficiency has been improved in each year, indicating that the low comprehensive technical efficiency before the adjustment is mainly due to the underestimated pure technical efficiency; the adjusted scale efficiency has declined, indicating that the listed company is in an unhealthy state in scale and needs to be reasonably expanded in future development. In general, the adjusted average technical efficiency is still at a low level, indicating that the overall level of innovation of listed companies in the Hubei Development Zone is low and there is much room for improvement.

From the perspective of the innovation efficiency of a single listed company, first of all, after our adjustment, the three at the forefront of comprehensive technical efficiency have been changed to five. Among them, the comprehensive technical efficiency of Guochuang High-tech, Liyuan Information, and Changjiang Communications has always been 1; it means that before our adjustment, those three companies are in a relatively poor environment, so the adjustment impact to them is small. Second, there are 16 companies increasing the overall technical efficiency, of which Fiberhome Communications has the largest increase. Third, there are 12 companies with pure technology efficiency growth and 10 companies with scale efficiency growth. Fourth, after adjustment, the increase in scale 
TABLE 5: Mean innovation efficiency before and after adjustment in each year.

\begin{tabular}{cccccc}
\hline Year & $\begin{array}{c}\text { Before adjustment } \\
\text { Comprehensive technical } \\
\text { efficiency }\end{array}$ & $\begin{array}{c}\text { Pure technical } \\
\text { efficiency }\end{array}$ & $\begin{array}{c}\text { Scale } \\
\text { efficiency }\end{array}$ & $\begin{array}{c}\text { After adjustment } \\
\text { Comprehensive technical } \\
\text { efficiency }\end{array}$ & $\begin{array}{c}\text { Pure technical } \\
\text { efficiency }\end{array}$ \\
efficiency \\
\hline 2012 & 0.612 & 0.745 & 0.795 & 0.654 & 0.880 \\
2013 & 0.563 & 0.710 & 0.798 & 0.578 & 0.721 \\
2014 & 0.449 & 0.727 & 0.609 & 0.604 & 0.626 \\
2015 & 0.439 & 0.707 & 0.651 & 0.548 & 0.930 \\
Mean & 0.516 & 0.722 & 0.713 & 0.596 & 0.826 \\
\hline
\end{tabular}

returns increased from 11 to 12 , the adjusted scale returns decreased to 8 , and the other 5 companies were in the same state of scale returns, indicating that expanding the scale of input factors is no longer an effective way to integrate technical efficiency for some of those enterprises.

\section{Analysis of Factors Affecting Innovation Efficiency Based on the Tobit Model}

According to our previous analysis, we found that there is a certain difference in the innovation efficiency between different enterprises, and the innovation efficiency of enterprises is affected by many factors. In this section, we will build a Tobit regression model based on the three-stage measurement results from the previous section. From the microlevel, we further study the influencing factors of the innovation efficiency of listed companies in the Hubei Development Zone.

4.1. Index Selection. With reference to domestic and foreign scholars' selection of indicators of influencing factors of corporate innovation efficiency, combined with the characteristics of listed companies in development zones, the following indicators are selected as influencing factors:

(1) Enterprise Scale. The size of a company has a huge impact on a company's position in the industry and its future development. A large-scale enterprise means that the company has strong human resources, material resources, and financial resources, which can provide multifaceted support for the company's innovation activities. A large-scale company has a stronger ability to resist the risks brought into the company by sudden market and financial issues. To ensure the continuity and stability of the company's innovation activities and thus to make sure of the realization of innovation results, this paper expresses the total assets of the enterprise scale [28]

(2) Enterprise Operating Capabilities. The operating capacity of an enterprise mainly refers to the efficiency and effectiveness of its operating assets. Among them, the efficiency of an enterprise's operating assets mainly refers to the turnover rate or turnover rate of assets. For those enterprises which have good operating capabilities, on the one hand, they can improve the financing efficiency of the enterprise, so as to provide protection for the company's investment in research development; in addition, higher operating capabilities are conducive to optimizing corporate assets structure, rationally allocating and using resources, and promoting the transformation of corporate innovation achievements. This paper will express the capability using total asset turnover [29]

(3) Years of the Establishment. The impact of the establishment period on the innovation efficiency of the enterprise is mainly reflected in the establishment time of the enterprise. With the change of time, the characteristics of enterprises in different life cycles and different competitive environments are also different. This paper expresses the measures by the years from the time when a company is registered to the reporting period [30]

(4) Quality of Workers. The quality of laborers is one of the core competitiveness that forms the competitiveness of enterprises. The level of laborers' quality as an intangible factor has a huge impact on the innovation efficiency of enterprises. The innovation level of an enterprise is often reflected by the innovation ability of employees. The improvement of the quality of workers is the source and motivation of innovation and development of enterprises. This paper uses the ratio of the number of masters and above the total number of employees to measure the quality of workers [31]

(5) State-Owned Shares. The state or state-owned legal person's participation in the company will be more strictly controlled to the financial risk and operational risk of the company; thereby, it will enhance the company's ability to resist risks, enabling the company to rationally allocate resources and improving innovation efficiency. In this paper, dummy variables are used to deal with the variables held by the state. 1 is the state or state-owned legal person holding the shares of the enterprise, and 0 is not holding the shares [32]

4.2. Tobit Regression Model Construction. We take the adjusted comprehensive technical efficiency of each company obtained in the previous section as the dependent variable; we can see that their efficiency values are between 0 and 1 . Therefore, the dependent variable data is a limited 
dependent variable. If we use ordinary least squares (OLS) regression, it will cause bias and large errors. Therefore, we decide to use the Tobit model when studying the factors that affect the innovation efficiency of listed companies in the Hubei Development Zone. The Tobit model was proposed by economist Tobin; the model belongs to a type of limited dependent variable (LDV) regression [33]. Its basic form is as follows:

$$
Y= \begin{cases}Y^{*}=\beta^{\prime} X+\mu, & Y^{*}>0, \\ 0, & Y^{*} \leq 0,\end{cases}
$$

where $Y$ is the dependent variable, $Y^{*}$ is the truncated dependent variable, $X$ is the independent variable, $\beta$ is the regression coefficient vector, $\mu$ is the error vector, and $\mu$ is independent and obeys $\mu \sim N\left(0, \sigma^{2}\right)$.

This paper uses the Tobit panel model under random effects to take the log of the company's total assets and establishment period. At last, we turn it into a relative indicator. Model 1 is constructed as follows:

$$
\begin{aligned}
Y 1_{j t}= & \beta_{1} \ln X 1_{j t}+\beta_{2} X 2_{j t}+\beta_{3} \ln X 3_{j t}+\beta_{4} X 4_{j t} \\
& +\beta_{5} X 5_{j t}+\mu 1_{j t},
\end{aligned}
$$

where $Y 1$ represents the adjusted comprehensive technical efficiency of the sample enterprises, $\ln X 1$ is the logarithmic value of the total assets of the enterprise, $X 2$ is the business operation capacity, $\ln X 3$ is the logarithm of the establishment period, $X 4$ is the quality of the laborer, $X 5$ is whether the country holds shares, $\beta_{1}$ is the regression coefficient of the independent variable, $\mu 1$ is the error vector, and $\mu 1$ is independent and obeys $\mu 1 \sim \mathrm{N}\left(0, \sigma^{2}\right)$.

4.3. Regression Results and Analysis. In order to adopt the random effect Tobit model for regression, we use STATA15.0 to regress panel data of 24 listed companies from 2012 to 2015. The results are shown in Table 6.

As the LR test results indicate in Table 6, it shows strong rejection " $H_{0}: \sigma_{u}=0$ ", so we believe that there is an individual effect, and the Tobit panel model under random effects further verifies the rationality of the model construction in this paper. From the value of Wald $\chi^{2}$, it can be concluded that model 1 passed the test at a significance level of $1 \%$, indicating that the regression equation constructed by model 1 is reasonable, and a specific analysis of each influencing factor index is made as follows.

First, the size of an enterprise has a significant positive impact on the overall technological efficiency. Large-scale enterprises generally have a larger market share and strong human resources and financial resources to provide support for innovation activities and ensure the development of innovation activities, which is conducive to the improvement of comprehensive technical efficiency. Second, the ability of a company to operate has a significant positive impact on the overall technical efficiency. The stronger the company's operating capabilities, the more competitive it is in the market and, therefore, the easier it is to gain the favor of capital; on the basis of stronger operating capabilities, companies can be promoting the development of corporate
TABLE 6: Tobit regression results.

\begin{tabular}{lc}
\hline Variable & Model 1 comprehensive technical efficiency \\
\hline Constant $(C)$ & $-1.59055(1.169232)$ \\
$\ln X 1$ & $0.1203022^{* *}(0.0538922)$ \\
$X 2$ & $0.5807479^{* * *}(0.2068644)$ \\
$\ln X 3$ & $-0.3263321^{* *}(0.1532586)$ \\
$X 4$ & $0.9765009(0.7176158)$ \\
$X 5$ & $0.2657279^{* *}(0.1184951)$ \\
Wald $\chi^{2}$ & $23.66^{* * *}$ \\
LR & $24.27^{* * *}$ \\
\hline
\end{tabular}

Note. $* * *, * *$, and $*$ indicate significance levels of $1 \%, 5 \%$, and $10 \%$, respectively. Standard deviations are in parentheses.

innovation activities and be forming a virtuous circle. Third, the establishment period has a significant negative impact on comprehensive technical efficiency, which is contrary to the previous analysis. After the enterprise has reached a certain scale, innovation may encounter bottlenecks, and a large number of funds will be required for market development, transformation, and upgrading and diversified development, which will cause the proportion of innovation investment to decrease, thereby making the innovation efficiency of the enterprise at a low level for a long time. Fourth, the quality of laborers has a positive impact on the overall technical efficiency but is not significant. The impact of highly educated personnel on innovation efficiency is not significant, which indicates that the listed companies in the development zone of Hubei Province do not make the best use of the highly educated personnel; this act causes a waste of talent to a certain extent. Fifth, state-owned shares have a significant positive impact on the overall technological efficiency. The development of an enterprise is inseparable from the impact of macroeconomic policies and politics. A state or stateowned legal person's participation in a company can make the company more sensitive to the environment and enhance its ability to resist risks, thereby focusing more on the development of innovative activities, and also can be more beneficial to the output of innovation results of those companies.

\section{Conclusions and Related Policy Recommendations}

5.1. Discussion and Conclusion. Through the research on innovation theory, enterprise innovation ability, and innovation efficiency, we use the three-stage DEA-Tobit model to conduct an empirical analysis of the innovation efficiency and its influencing factors of 24 listed companies in Hubei Development Zone from 2012 to 2017. Among the 24 listed companies in the development zone, there are 15 in the East Lake High-tech Zone, known as Wuhan Optics Valley, mainly in the optoelectronics, communications, and laser industries, and the remaining 9 companies are located in Xiangyang, Yichang, and other regions; they are economically connected with Hubei. This is consistent with the pattern of "one major city and two secondary cities." The specific discussion of data analysis and empirical results show the following: 
(1) The innovation capability of listed companies is a comprehensive capability. The overall innovation efficiency of listed companies in the Hubei Development Zone is relatively low. The adjusted average annual innovation efficiency is under 0.6, the lowest in 2015 was 0.439 , and the average technical innovation efficiency of Chinese listed companies in the conclusion of [11] is about 0.7 . It means that our average annual innovation efficiency is at a low level. The empirical analysis results show that the levels of innovation efficiency of listed companies in Hubei Development Zones vary widely. A four-year sample, after adjusting the innovation efficiency average, shows that there are seven companies between 0.8 and 1 , seven other companies between 0.5 and 0.8 , and ten of the rest below 0.5. Among these companies, the highest is Optical Motion Technology and Fiberhome Communications, with an efficiency value of 1, which fully reflects the characteristics of the East Lake High-tech Optics Valley industry. The innovation efficiency of other industries such as Renfu Technology, Dongfeng Motor, and Jingshan Light Machinery is relatively low, which is also related to their industry and geographical location. The lowest is Steyr with an efficiency value of only 0.107. The company is an ST company. From the annual report, the company is involved in a number of lawsuits and huge financial borrowings could not be repaid. Most of the $R \& D$ projects have been terminated, and the innovation capacity is seriously insufficient

(2) Environmental variables have a significant impact on innovation efficiency. Four have a significant impact on innovation efficiency: the environmental variables of the number of enterprises, government subsidies, foreign direct investment in development zones, and investment in fixed assets, indicating that the above variables are conducive to enterprise innovation. After we exclude environmental factors and random interference factors, the efficiency has been improved, indicating that the innovation efficiency of listed companies is adversely affected by the environment. Consistent with the conclusion of the impact of external environment on enterprise efficiency in [10], environmental factors have a significant impact on enterprise innovation efficiency $[11,34]$; that is, government-supported to high-tech industrial technology innovation policies and government systems need to increase their support and enhance the trade-off of configuration efficiency [34, 35 ] to ensure maximum innovation efficiency

(3) The scale of the enterprise, the company's operating capacity, and state-owned shares have a significant positive impact on innovation efficiency. The number of years of the establishment has a significant negative impact on innovation efficiency. The quality of workers has no significant impact on innovation efficiency. This indicates that two listed companies should further increase the scale of enterprises, operating capacity, and state-owned shares. The number of years of establishment indicates that after the listed companies have developed to a certain size, bottlenecks in innovation and development have emerged. It is necessary to transform, upgrade, and realize the conversion of new and old kinetic energy. In the conclusion of [10], it mentioned that the efficiency of innovation and R\&D is subject to low-scale efficiency [35], which is consistent with the research conclusions of this paper. It is mentioned that technological progress [32], scale efficiency, and high-tech industrial resource allocation [11] are the core drivers of enterprise development, and the adverse environment has a bad impact on enterprises, but it also shows that, in the current stage, the technological innovation efficiency of Chinese enterprises has a lot of space to improve

5.2. Policy Recommendations. According to the "China development zone review announcement catalogue (2018 edition)," the number of national development zones in Hubei Province has increased to 22 (including 7 in the economic development zone, 12 in the high-tech zone, and 3 in the special customs supervision zone), and the number of companies in Hubei Province is in the middle level of China. And all listed companies are all distributed in national development zone levels. This research analyzes the innovation efficiency and influencing factors of listed companies in the Hubei Province from the perspective of innovation efficiency of listed companies in the Hubei Development Zone. According to the research conclusions, relevant policy suggestions can be put forward from the following aspects:

(1) Deepen the reform of the system and mechanism of the development zone and, therefore, revitalize the innovation of companies. First, to further improve the management system, we must actively implement the spirit of the state council's opinions on promoting the innovation and enhancement of national economic and technological development zones and creating new heights of reform and opening (issued by the state council [2019] no. 11) and accelerate the formulation and promulgation of the "regulations on development zones in Hubei province." The district regulations of Hubei province encourage enterprises to expand their scale, enhance their operational capabilities, and improve their innovation capabilities. The second step is to optimize the industrial structure of the high-tech zone in accordance with the characteristics of the East Lake High-tech Zone in Hubei, further strengthen the R\&D and innovation capabilities of optoelectronic communications, and create a new wave of innovation in the East Lake High-tech Zone

(2) Strengthen the top priority of a talented person, and create a new high ground for the development of "high-precision and scarce" talented people. 
Environmental factors indicate that highly educated personnel have not been used reasonably in the listed companies in Hubei Development Zone, and there is a certain waste of talented people. On the one hand, it is recommended that the government learned the "10 beautiful jade" terms from the Guangzhou development zone and take the "high-skilled shortage" as the guide to build a platform for the connection of scientific and technological talents and industries to attract Nobel prize winners, national highest science and technology award winners, and various highlevel incremental talents, including academicians, thus to improve the originality and level of innovation of listed companies. On the other hand, enterprises should establish a perfect incentive mechanism to fully mobilize the enthusiasm of highly educated personnel in corporate innovation activities, tap the potential of highly educated talents, promote the realization of innovation results, and improve the innovation ability to find talents

(3) Increase investment in innovation, strengthen the main body of innovation, deepen cooperation between government, industry, university, and research institutes, improve the business environment, and enhance innovation capabilities. First of all, we must increase financial support for the transformation and upgrading of national development zones and for innovation and development. The government's innovation-led investment has steadily increased, leading high-tech enterprises in development zones to increase investment in research and development, and continuously increasing the proportion of R\&D in national development zones. The second step is to strengthen the subject of innovation, guide various types of innovation factors to gather to work for listed companies, make enterprises as the main subject of innovation decisionmaking, R\&D investment, scientific research, and achievement transformation, accelerate the cultivation of a group of innovative listed companies, and consolidate the main body of innovation. The third is to deepen the cooperation between industry, universities, and researchers, make full use of the advantages of Hubei Province in science and education to build a group of industry-university-research cooperation innovation platforms, industrial technology innovation bases, industrial technology innovation strategic alliances, and collaborative innovation centers, and break the "bottleneck" in the transformation of scientific and technological achievements. The fourth is to learn from Xiamen's "no need to go to the government departments for administrative approval" terms and Zhejiang's "handle all administrative approvals through one online platform" experience, promote "one window acceptance, integrated services," and create a "onetime submission, simultaneous processing, information sharing, time-limited settlement" process to improve government services efficiency and the foreign investment environment

Finally, our research "Relying on National Development Zones to Create Hubei Kinetic Energy Conversion Pilot Zone" has been submitted to the Hubei provincial government in the form of a government special report, received the approval of the governor of Hubei Province, and forwarded to the reform commission for application; finally, we formed a number of relevant government documents.

\subsection{Research Limitations}

(1) The time span of data is short. In the future, after statistical data becomes more complete, a wider time span can be conducted to draw more accurate conclusions.

(2) About the selection of samples, those listed companies in the development zone in every province in China should be selected as the sample to study the differences in innovation efficiency in the future, so that the research will be more universal.

\section{Data Availability}

The data used in this study are from the Guotai' an database, the annual report of listed companies, and the "Hubei Statistical Yearbook." The Excel data used to support the findings of this study are included within the supplementary information file.

\section{Conflicts of Interest}

The authors declare no conflicts of interest.

\section{Authors' Contributions}

Conceptualization was performed by P. X.; methodology and investigationwere carried out by P. X.; data analysis was achieved by Z. Y. Z.; writing and review were carried out by P. X and H. Y. X.; supervision was done by F. L. and H. Y. X.

\section{Acknowledgments}

This work was partially supported by the National Natural Science Foundation of China (Grant number: 71672136).

\section{References}

[1] Z.-X. Du, L.-P. Zheng, and Y.-G. Liu, Schumpeter's Theory of Economic Development, China Commercial Press, Beijing, China, 2009.

[2] Z.-H. Zhang, Y.-W. Wang, L. Yan, and X. Q. Xu, "Research on evaluation of listed companies' innovation capability—data from 41 listed companies in Shaanxi province," Scientific Research Management, vol. 37, no. 3, pp. 81-92, 2016.

[3] M. Squicciarini, "Science parks: seedbeds of innovation? a duration analysis of firms' patenting activity," Small Business Economics, vol. 32, no. 2, pp. 169-190, 2009. 
[4] Y.-F. Lin, W. Xiang, and M.-J. Yu, "Regional industrial policy and enterprise productivity," Economics, vol. 17, no. 2, pp. 781-800, 2018.

[5] O. Movshuk, "Restructuring, productivity and technical efficiency in China's iron and steel industry, 1988-2000," Journal of Asian Economics, vol. 15, no. 1, pp. 135-151, 2005.

[6] M. B. Aryanezhad, E. Najafi, and S. B. Farkoosh, "A BSC-DEA approach to measure the relative efficiency of service industry: a case study of banking sector," International Journal of Industrial Engineering Computations, vol. 2, no. 2, pp. 273-282, 2005.

[7] L.-H. Liang, H.-F. Zhang, and Y. Yuan, "Study on the efficiency of enterprise R\&D based on DEA," Scientific Resource management, vol. 6, pp. 68-73, 2006.

[8] C. Zhang, Study on Economic Efficiency Evaluation of China High-Tech Industrial Development Zones, Shanxi University of Finance and Economics, Taiyuan, China, 2018.

[9] P. Li and L. Liu, "Government R\&D funding, enterprise R\&D investment and China's innovation efficiency," Scientific Resource management, vol. 38, no. 1, pp. 21-29, 2017.

[10] L.-W. Cheng, W. Sun, and J.-Y. Wang, "Innovation efficiency of high-tech industry from the perspective of incomplete factor market-comparison of the efficiency of allocation of domestic and foreign capital and scale efficiency based on three-stage DEA-windows," Science Research, vol. 29, no. 6, pp. 930-938, 2011.

[11] G.-J. Qu, L. Song, and Y.-J. Guo, "Research on the technological innovation efficiency of Chinese listed companies-based on the three-stage DEA method," Macroeconomic Research, vol. 6, pp. 97-106, 2018.

[12] D.-P. Zhang and B.-Y. Shu, "An empirical study on the operating efficiency of Chinese star hotels and its influencing factors: based on the stochastic frontier analysis method (SFA)," Economic Management, vol. 40, no. 9, pp. 138-154, 2018.

[13] A. Hashimoto and S. Haneda, "Measuring the change in R\&D efficiency of the Japanese pharmaceutical industry," Research Policy, vol. 37, no. 10, pp. 1829-1836, 2008.

[14] M.-J. Farrel, "The measurement of productive efficiency," Journal of the Royal Statistical Society: Series A, vol. 120, no. 3, pp. 253-281, 1957.

[15] A. Charnes, W. W. Cooper, and E. Rhodes, "Measuring the efficiency of decision making units," European Journal of Operational Research, vol. 2, no. 6, pp. 429-444, 1978.

[16] H. O. Fried, C. A. K. Lovell, and S. S. Schmidt, "Accounting for environmental effects and statistical noise in data envelopment analyssis," Journal of Productivity Analysis, vol. 17, no. 1-2, pp. 157-174, 2002.

[17] A. Ebrahimnejad, M. Tavana, F. H. Lotfi, R. Shahverdi, and M. Yousefpour, "A three-stage data envelopment analysis model with application to banking industry," Measurement, vol. 49, pp. 308-319, 2014.

[18] L. Li, "Research on efficiency of information industry of China based on the three-stage DEA model," Statistics and Decision, vol. 340, pp. 84-86, 2011.

[19] J. Liu and W. Li, "Efficiency measures of the internet company in China using a three-stage DEA model," Pakistan Journal of Statistics, vol. 30, no. 5, pp. 567-588, 2014.

[20] D.-Y. Luo, "Notes on the inefficient estimation of the threestage DEA model management," Statistical Research, vol. 29, no. 4, pp. 105-108, 2012.

[21] B.-F. Liu and X.-M. Wang, "Research on operating efficiency of culture media listed companies based on three-stage data envelopment analysis model," Journal of Mathematics in Practice and Theory, vol. 2, pp. 119-133, 2019.

[22] C. J. James, A. K. Lovell, S. M. Ivan, and S. Peter, "On the estimation of technical inefficiency in the stochastic frontier production function model," Journal of Econometrics, vol. 19, no. 2-3, pp. 233-238, 1982.

[23] R. D. Banker, A. Charnes, and W. W. Cooper, "Some models for estimating technical and scale inefficiencies in data envelopment analysis," Management Science, vol. 30, no. 9, pp. 1078-1092, 1984.

[24] X.-H. Wang, M.-H. Wang, and X.-J. Li, "Measurement of innovation performance of listed companies in strategic emerging industries," Jiangxi Social Sciences, vol. 35, no. 6, pp. 35-40, 2015.

[25] Y.-B. Wu, "Estimation of China's industrial R\&D output elasticity," Economics, vol. 3, pp. 869-890, 2008.

[26] W.-J. Yu, L.-H. Ma, and H.-X. Li, "Research on regional hightech industry innovation efficiency and influencing factors based on two-stage DEA," Research and Development Management, vol. 27, no. 3, pp. 137-146, 2015.

[27] K. Pavitt, M. Robson, and J. Townsend, "The size distribution of innovating firms in the UK: 1945-1983," The Journal of Industrial Economics, vol. 35, no. 3, pp. 297-316, 1987.

[28] Y. Liao, Y.-J. Shen, and X.-S. Yang, "Research on the financing efficiency of SMEs on the new third board and its influencing factors," Friends of Accounting, vol. 11, pp. 49-53, 2017.

[29] G.-Q. Zhao, "Efficiency evaluation of Chinese life insurance companies and analysis of its influencing factors-a modified two-stage data envelopment analysis method," Insurance Research, vol. 10, pp. 38-44, 2009.

[30] M.-M. Deng, Research on Technology Innovation Efficiency of GEM Listed Companies and its Influencing Factors, Shanghai International Studies University, Shanghai, China, 2017.

[31] J.-J. Wang, J. Qiu, and Q.-T. Yu, "Measurement of financing efficiency of Chinese manufacturing listed companies in the small and medium-sized board market-based on the threestage DEA-malmquist model," Contemporary Finance Research, vol. 5, pp. 68-80, 2018.

[32] J. Tobin, "Estimation of relationships for limited dependent variables," Econometrica, vol. 26, no. 1, pp. 24-36, 1958.

[33] H.-H. Liu, "Applying three-stage DEA on the operational performance of foreign banks in Taiwan," International Review of Applied Economics, vol. 32, no. 1, pp. 104-118, 2018.

[34] J. Sun, N. Ruze, J. Zhang, H. Zhao, and B. Shen, "Evaluating the investment efficiency of China's provincial power grid enterprises under new electricity market reform: empirical evidence based on three-stage DEA model," Energies, vol. 12, no. 18, pp. 1-17, 2019.

[35] H. Li, H. He, J. Shan, and J. Cai, "Innovation efficiency of semiconductor industry in China: a new framework based on generalized three-stage DEA analysis," Socio-Economic Planning Sciences, vol. 66, pp. 136-148, 2019. 